\title{
THE JOURNAL.
}

The Editors have attempted in the present issue to improve the form, type, and outward appearance of the JourNal as far as this was possible without adding inaterially to the cost of production. The alterations will speak for themselves, and the Editors trust that members of the Association, remembering the above limitation, will find the changes improvements, rendering the Journal more worthy of the important interests which it now represents.

The Editors enclose an appeal to the Members of the Association to aid them in increasing the monetary prosperity of the JOURNAL, in which, they believe, much might be done by united effort.

\section{CRAIG COLONY PRIZE FOR ORIGINAL RESEARCH IN EPILEPSY.}

The President of the Board of Managers of Craig Colony offers a prize of $\$ 100$ for the best contribution to the pathology and treatment of epilepsy, originality being the main condition. The prize is open to universal competition, but all manuscripts must be submitted in English. All papers will be examined by a Committee to consist of three members of the New York Neurological Society, and the award will be made at the annual meeting of the Board of Managers of Craig Colony, October roth, 1899 .

Each essay must be accompanied by a sealed envelope containing the name and address of the author, and bearing on the outside the motto or device which is inscribed upon the essay. The successful essay becomes the property of the Craig Colony for publication in its Annual Medical Report.

Manuscripts should be sent to Dr. Frederick Peterson, 4 West 5oth Street, New York City, on or before September Ist, 1899 .

\section{RESIGNATION}

Dr. Symes Saunders has retired from the office of medical superintendent to the Devon County Asylum, having recently entered on the fortieth year of his service in that institution. The venerable chairman, Mr. Saunders, who has been connected with the Devon County Asylum ever since it was opened, in the course of an appreciative speech on the occasion of Dr. Saunders' resignation, reviewed the financial history of the institution, and moved that a pension of 6742 10s. per annum be granted. This sum had been arrived at on a calculation of two thirds of the salary and emoluments. We congratulate Dr. Saunders on the finding of the County Council, and express the hope that he will enjoy his retirement after so many years of work. It may be noted that an attempt to arrive at an understanding with his successor, to the effect that a pension would not necessarily follow on his service, was ruled out of order by the chairman of the County Council.

\section{PRESENTATIONS}

At the Warneford Asylum, Oxford, Dr. Neil had recently the pleasant duty of presenting to Mr. Matthews, the chief attendant, who has captained the cricket club for thirty-seven years, a handsome clock; and to Dr. Goldie-Scot, who has served as assistant medical officer for the past year, a marble timepiece and other souvenirs from the patients. We record these incidents with pleasure. 